\title{
MCC/IMS as potential noninvasive technique in the diagnosis of patients with COPD with and without alpha 1-antitrypsin deficiency
}

\author{
Rembert Koczulla • Akira Hattesohl • Severin Schmid • \\ Bertram Bödeker • Sasidhar Maddula • \\ Jörg Ingo Baumbach
}

Received: 20 June 2011 / Accepted: 27 June 2011 /Published online: 20 July 2011

(C) The Author(s) 2011. This article is published with open access at Springerlink.com

\section{Background}

Chronic obstructive lung disease (COPD) is characterized by a not fully reversible and usually progressive airflow limitation. The disease is associated with an inflammatory response of the lungs to noxious particles, mainly cigarette smoke but also alpha 1-antitrypsin (AAT) deficiency predisposes to COPD. The usual clinical practice for diagnosing COPD is following symptoms, performing lung function and the assessment of responses to inhaled pharmacological agents. These tests have been standardized and are generally considered as informative [1]. The tests are time consuming. Still the quality of the tests is influenced by experience and may differ depending where the tests are performed. Further, it is suggested that every COPD patient is once screened for AAT deficiency (AATD). Alpha 1-antitrypsin deficiency is a co-dominant

R. Koczulla $(\bowtie) \cdot$ A. Hattesohl $\cdot$ S. Schmid

Zentrum für Innere Medizin - Pneumologie,

Universitätsklinik Gießen und Marburg,

Standort Marburg, Baldingerstraße,

35043 Marburg, Germany

e-mail: koczulla@med.uni-marburg.de

B. Bödeker

B\&S Analytik, BioMedicalCenter,

Otto-Hahn-Str. 15,

44227 Dortmund, Germany

S. Maddula $\cdot$ J. I. Baumbach

Department Microfluidics and Clinical Diagnostics, KIST Europe, Campus E 71,

66123 Saarbrücken, Germany inherited disorder that is diagnosed by low serum levels, genotyping and phenotyping of AAT.

Usually the serum AAT levels are analyzed first. If the serum levels are decreased further procedures like genotyping (with polymerase chain reaction) and phenotyping (isoelectric focusing) are suggested. The costs of these diagnostic procedures are high [2] and therefore often not carried out. Thus, there is a need for novel diagnostic methods that are simple, fast and cost-effective and maybe performed bedside. Within the past decade, cellular and molecular techniques have been utilized as options for the diagnosis and monitoring of COPD and AAT deficiency [3].

The analysis of exhaled breath (EB) has been used to noninvasively obtain information about inflammatory processes within the lung. EB contains a complex mixture of volatile organic compounds (VOCs), which can be detected using gas chromatography-mass spectrometry (GC-MS) [4]. Electronic noses (eNoses) use a concept essentially different from GC-MS. In addition, they allow the online recognition of complex VOC mixtures via composite nanosensor arrays in combination with learning algorithms $[5,6]$. Another approach is the ion mobility spectroscopy (IMS), were about $10 \mathrm{ml}$ human breath will be analyzed directly and without any pre-enrichment. Two different types of IMS, such coupled to multi-capillary columns (MCC/IMS) [7-15] and differential mobility spectrometers $[16,17]$ were used.

It is currently assumed that COPD with or without AAT deficiency shows different molecular and cellular characteristics due to the pathophysiological inflammation present in AAT deficiency [18]. Thus, it may be that the VOC profile or smellprint is different in the EB of patients with COPD 
Table 1 Characteristics of ion mobility spectrometer (BioScout 2010)

\begin{tabular}{ll}
\hline Parameter & Value \\
\hline Ionization source & ${ }^{63} \mathrm{Ni}(555 \mathrm{MBq})$ \\
Electric field strength & $320 \mathrm{~V} / \mathrm{cm}$ \\
Length of drift region & $12 \mathrm{~cm}$ \\
Diameter of drift region & $15 \mathrm{~mm}$ \\
Length of ionization chamber & $15 \mathrm{~mm}$ \\
Shutter opening time & $300 \mu \mathrm{s}$ \\
Shutter impulse time & $100 \mathrm{~ms}$ \\
Drift gas & synthetic air $\left(20.5 \% \mathrm{O}_{2}(4.5), 79.5 \% \mathrm{~N}_{2}(5.0)\right)$ \\
Drift gas flow & $100 \mathrm{ml} / \mathrm{min}$ to $300 \mathrm{ml} / \mathrm{min}$ \\
Pressure & $101 \mathrm{kPa}(\mathrm{ambient} \mathrm{pressure})$ \\
Multi-capillary column & $\mathrm{OV}-5$, polar \\
Column temperature & $40{ }^{\circ} \mathrm{C}$
\end{tabular}

with and without AAT deficiency. Based on this possibility, it was the aim of our study to compare smellprints between COPD patients with confirmed AAT deficiency and COPD patients without AAT deficiency. In another approach also the influence of AAT augmentation therapy should be studied. Patients with severe AATD can be treated with weekly AAT infusions (60 mg/kg body weight). This therapy regimen is based on studies showing an increase of AAT lung levels as well as an increase of the antineutrophil elastase capacity in the epithelial lining fluid of the lung [1]. Considering this, an influence of the augmentation on the smellprint of AATD patients seems
Fig. 1 IMS chromatograms before and after AATD augmentation

\section{Before augmentation}

After augmentation
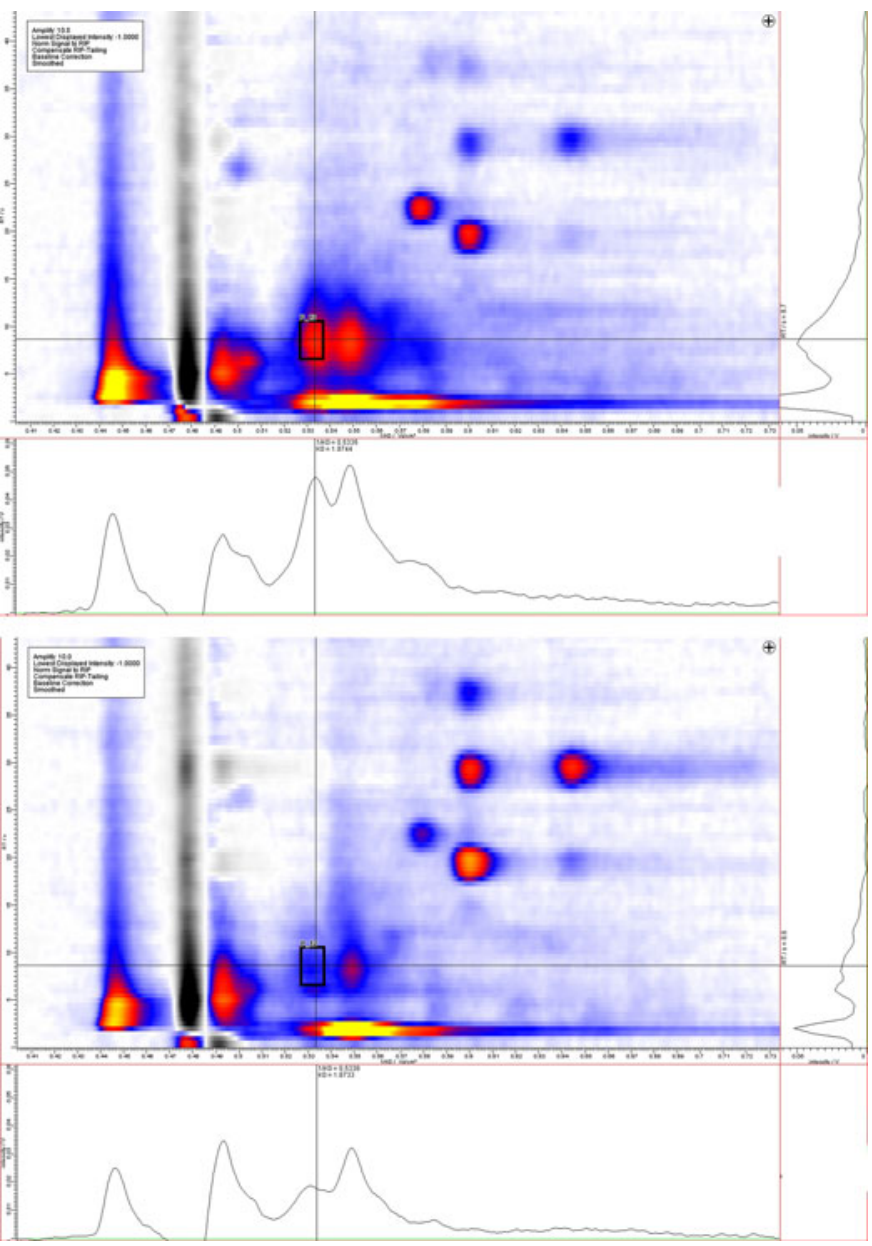
reasonable. Hence, the second aim of the study was to detect the influence of intravenously given AAT on the composition of VOCs in EB of AATD patients.

\section{Patients}

We included patients with genetically proved severe AATD (PiZZ genotype). All patients were fasting for at least $2 \mathrm{~h}$. Patients had to wash out their mouth with water. For sampling the patients breathed into the device. For every breath the first expiratory $40 \mathrm{ml}$ were discarded to exclude air of the oral cavity. The patients breathed until $10 \mathrm{ml}$ of expiratory air (excluding the oral cavity) were obtained by the device for sampling. From AATD patients breath samples were taken twice, directly before and $2 \mathrm{~h}$ past their infusion or augmentation. The numbers of breath samples included within the two different cases investigated are:

- Before and after substitution: 2

- COPD without AATD: 8

- COPD based on AATD: 17.

Fig. 2 Box-and-whisker plots related to increasing and decreasing signals, before and after AATD augmentation

\section{Method}

The IMS coupled to a multi-capillary column (MCC/IMS) used was a BioScout (B\&S Analytik, Dortmund, Germany) consisting of the MCC/IMS and a SpiroScout (Ganhorn Medizin Electronic, Niederlauer, Germany) as sample inlet unit. The major parameters are summarized elsewhere [812, 19-23]. In this spectrometer a $550 \mathrm{MBq}{ }^{63} \mathrm{Ni} \beta$ radiation source was applied for the ionization of the carrier gas (air). It was connected to a polar multi-capillary column (MCC, type OV-5, Multichrom Ltd, Novosibirsk, Russia) used as the pre-separation unit. In this MCC the analytes of exhaled breath were sent through 1000 parallel capillaries, each with an inner diameter of $40 \mu \mathrm{m}$ and a film thickness of $200 \mathrm{~nm}$. The total diameter of the separation column was $3 \mathrm{~mm}$. The relevant MCC parameters are listed in Table 1.

All subjects were requested to exhale through a mouth piece connected to a Teflon tube. In each case end-tidal breath, controlled by a flow sensor, was collected in a sample loop of $10 \mathrm{ml}$ volume. The sample air was collected and transferred to the multi-
Increase:
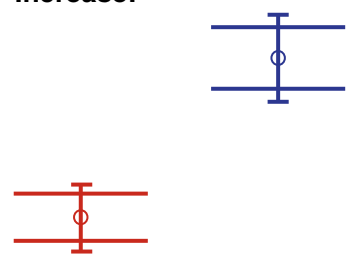

PRE

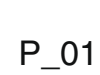

Decrease:
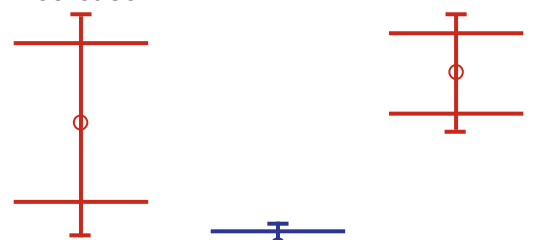

POST

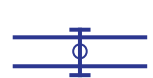

PRE

P_54

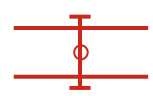

PRE

PRE
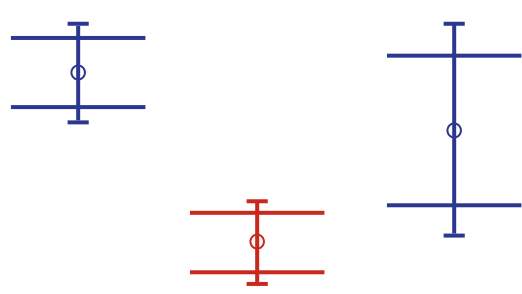

POST

P_07

PRE

POST

P_09
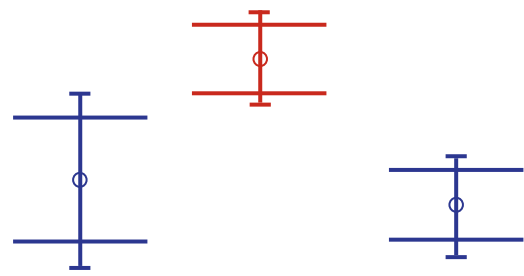

POST

P_02

PRE

POST

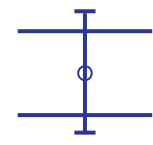

PRE

POST 
Table 2 Position of the signals discriminating AATD before and after augmentation

\begin{tabular}{llllll}
\hline$\#$ & Area & Norm U & $1 / \mathrm{K}_{0} \mathrm{VS} / \mathrm{cm}^{2}$ & $\mathrm{RT} / \mathrm{s}$ & Nearest analyte \\
\hline 1 & P_01 & 0.000 & 0.579 & 1.7 & Butanole \\
2 & P_02 & 0.000 & 0.550 & 2.3 & Acetone \\
3 & P_07 & 0.000 & 0.584 & 6.0 & 2-Hexanone \\
4 & P_09 & 0.000 & 0.607 & 6.3 & 1-Pentanole \\
5 & P_10 & 0.000 & 0.569 & 6.3 & 1-Butanole \\
6 & P_11 & 0.000 & 0.531 & 6.2 & 2-Butanone \\
7 & P_12 & 0.000 & 0.532 & 8.6 & 2-Propanole \\
8 & P_13 & 0.000 & 0.578 & 8.1 & 2-Hexanone \\
9 & P_14 & 0.000 & 0.550 & 8.6 & 3-Pentanone \\
10 & P_18 & 0.000 & 0.562 & 17.0 & 2,5-Dimethylpyrazine \\
11 & P_22 & 0.000 & 0.581 & 23.0 & 1,2,4-Trimethylbenzene \\
12 & P_28 & 0.000 & 1.073 & 29.4 & unknown \\
13 & P_41 & 0.000 & 0.608 & 45.8 & unknown \\
14 & P_42 & 0.000 & 0.641 & 51.7 & unknown \\
15 & P_44 & 0.000 & 0.576 & 55.6 & 1,2-Butandiole \\
16 & P_50 & 0.000 & 0.598 & 73.6 & unknown \\
17 & P_54 & 0.000 & 0.664 & 77.4 & Menthon \\
18 & P_56 & 0.000 & 0.735 & 77.7 & unknown \\
19 & P_60 & 0.000 & 0.668 & 84.4 & unknown \\
20 & P_62 & 0.000 & 0.607 & 88.5 & unknown \\
21 & P_64 & 0.000 & 0.616 & 96.9 & unknown \\
22 & P_65 & 0.000 & 0.760 & 95.4 & unknown \\
\hline & & & &
\end{tabular}

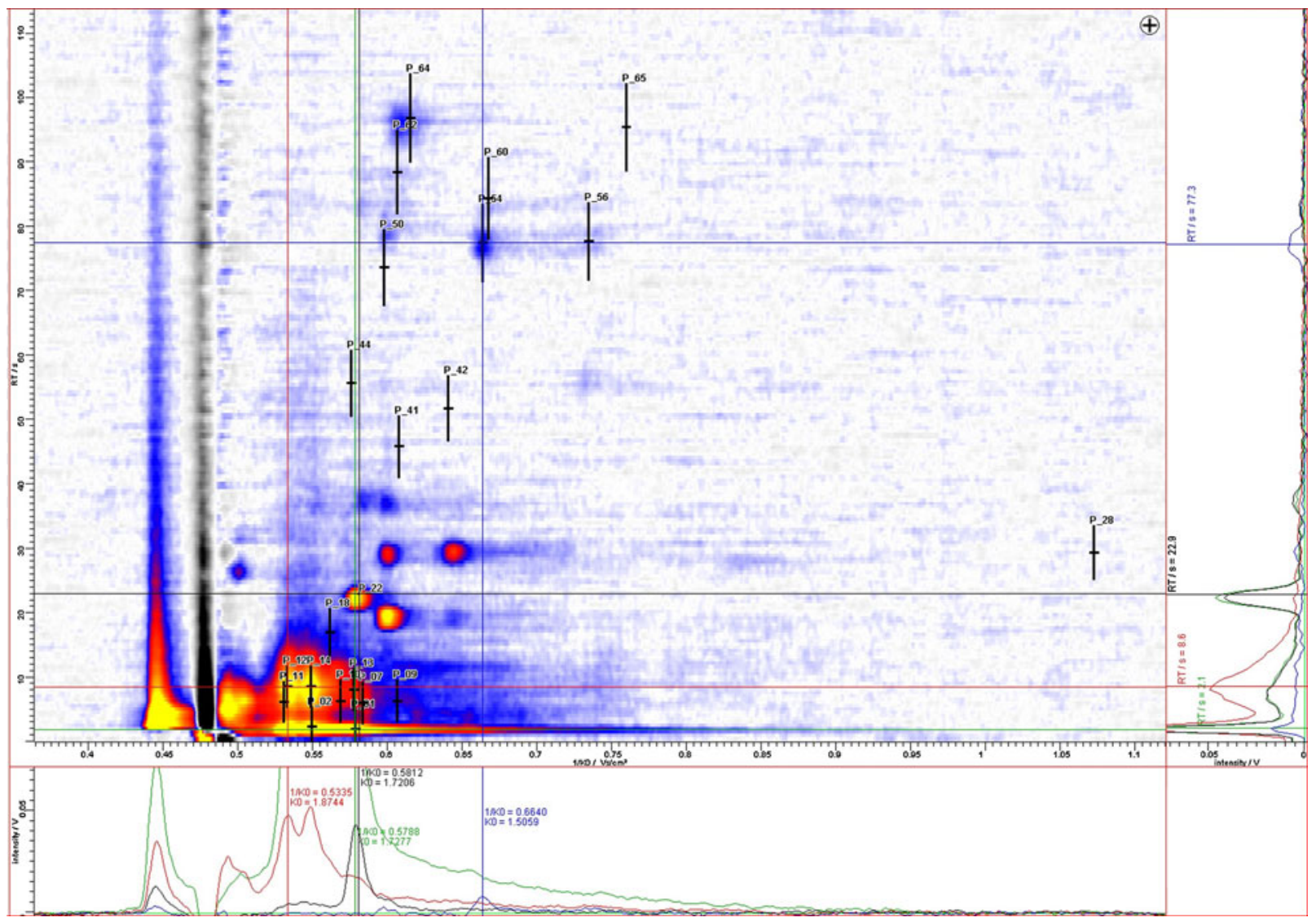

Fig. 3 Signals of potential relevance to AATD within the IMS chromatogram 
capillary column for a first chromatographic separation after reaching 3 times $10 \mathrm{ml}$ above the dead volume. Using the software VOCan 1.4 (B\&S Analytik, Dortmund, Germany) the dead volume was adjustable and fixed in the present case to $500 \mathrm{ml}$. The expiration was controlled by a $\mathrm{CO}_{2}$ sensor element integrated in the SpiroScout and recorded for each subject.

The peaks were characterized using the software Visual Now 2.2 (B\&S Analytik, Dortmund, Germany), which is described elsewhere [8, 24-27]. All peaks found are characterized by their position with drift time (corresponding $1 / \mathrm{K}_{0}$-value), retention time and their concentration represented by the peak height. For both groups and each of the peaks a box-and-whisker plot was realized.

A preliminary relation between the peak position and the identity of the analyte was obtained using the database BSIMSDB 1.4 (B\&S Analytik, Dortmund, Germany), but parallel measurements using e.g. GC/MSD (gas chromatography/mass selective detector) should be realized with respect of further confirmation.

\section{Results}

We compare two different cases

- IMS chromatograms before and after substitution

- AATD and COPD (without AATD), here we describe differences between COPD without AATD and COPD based on AATD.

The IMS chromatograms before and after AAT augmentation are compared in Fig. 1. The signal with the highest rank sum is marked by black rectangles. The box-and-whisker plots related to increasing and decreasing signals, before and after AAT augmentation are shown in Fig. 2. Totally, 22 different signals were found with rank sum 0.00 , the best value. The positions were reported in Table 2 and shown in Fig. 3. It should be noted, that because of the preliminary status of the study and the rather low number of subjects included so far, the findings need confirmation within a larger group, but should encourage investigations of exhaled breath to identify potential biomarkers.
Fig. 4 Signals of AATD and COPD without AATD within IMS chromatograms

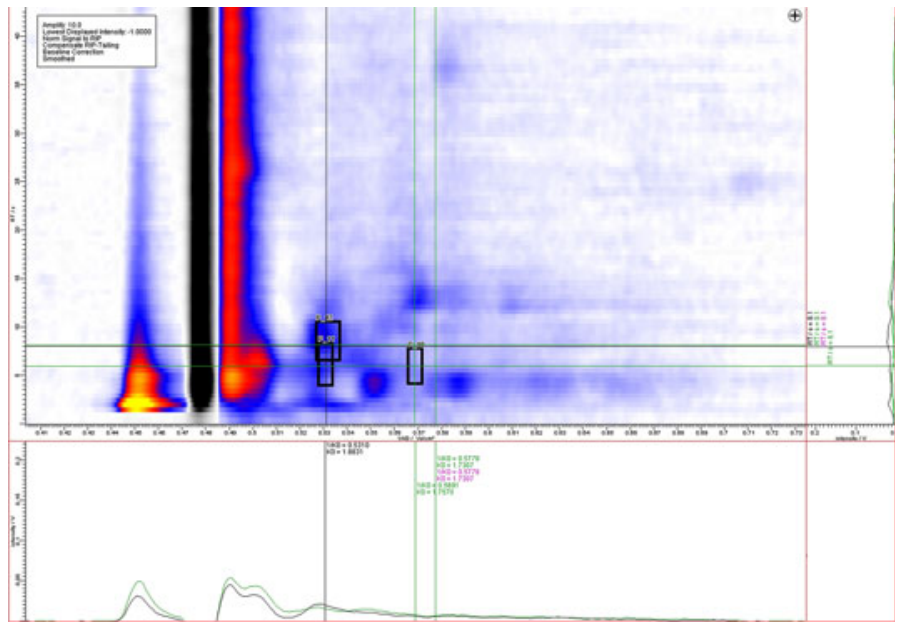

COPD without AATD

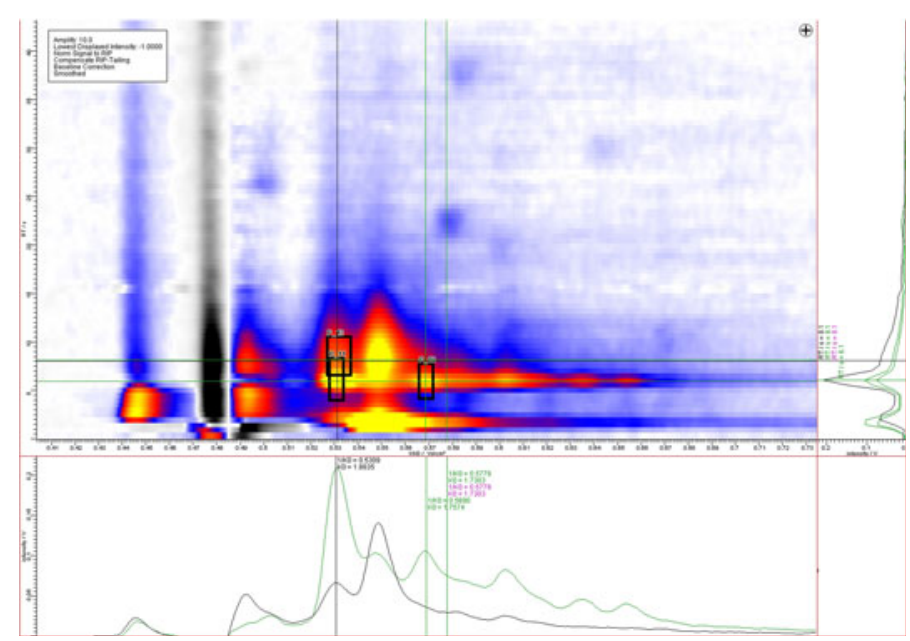


Fig. 4 (continued)
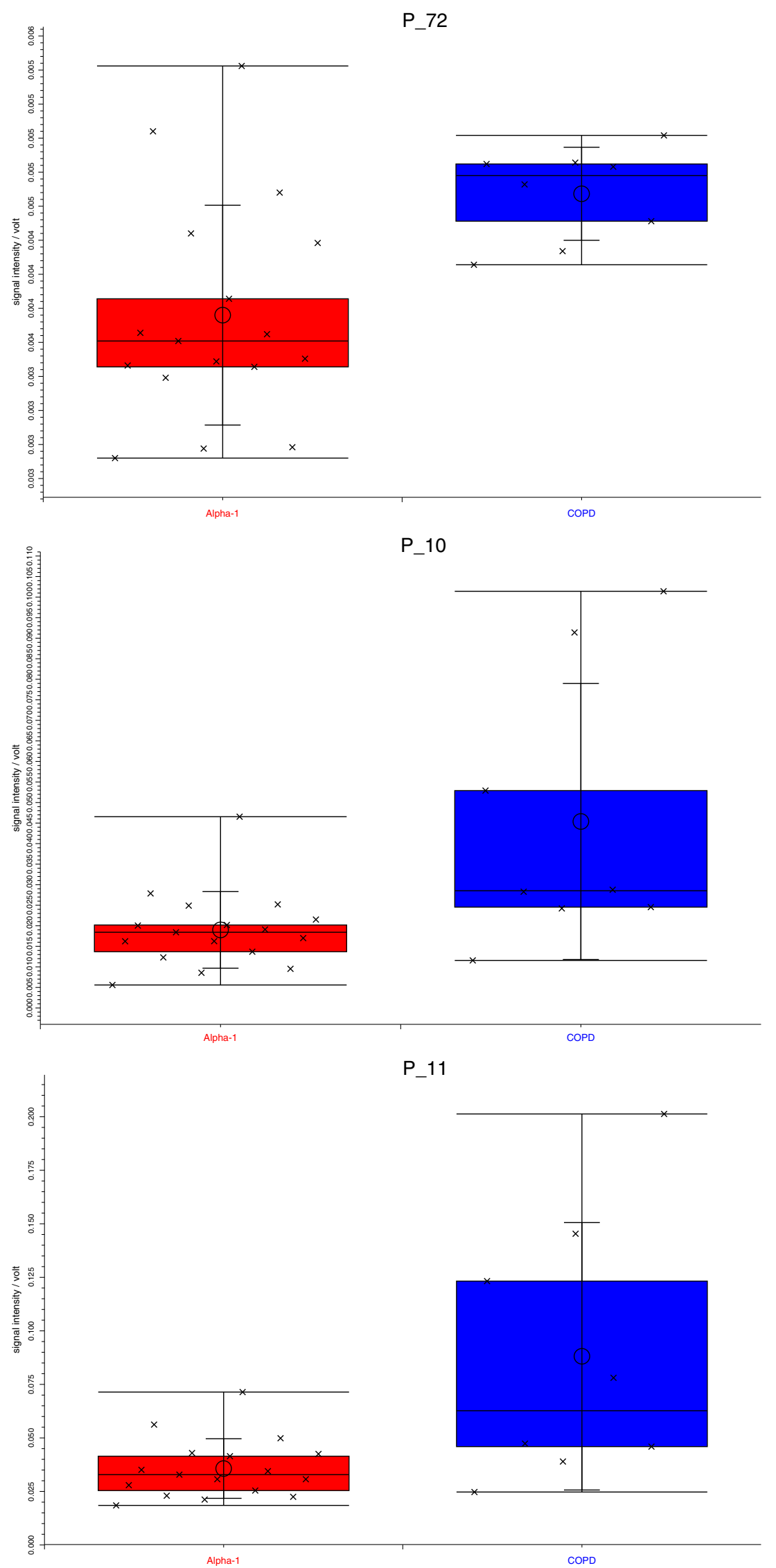
Fig. 5 Box-and-whisker plots of signals potentially separating AATD and COPD without AATD
Furthermore, the signals $\mathrm{P}_{-} 10, \mathrm{P}_{-} 11, \mathrm{P}_{-} 12$ and $\mathrm{P}_{-} 13$ should be considered also in relation to case two, dealing with the difference between COPD without AATD and COPD based on AATD.

Typical IMS chromatograms for case two are shown in Fig. 4. Some peaks useful for discrimination between COPD with and without AATD are marked. The box-andwhisker plots for the five signals with the lowest rank sum with respect to a potential separation between the two groups investigated are shown in Fig. 5 and described in Table 3. In nearly all cases the signal within the group of COPD without AATD is higher than in AATD.

In the group of COPD with and without AATD the numbers of patients were higher than in case before and after substitution. Therefore, in Table 4 the values of accuracy, sensitivity, specificity and the positive and negative predictive
P_12

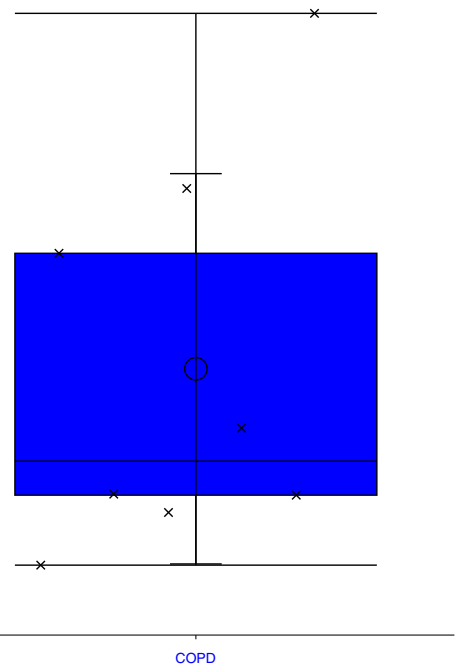

P 13
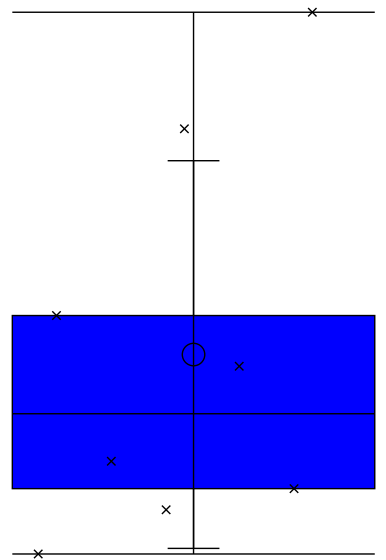

COPD value are shown for the five peaks with the rank sum less than 0.2. In addition, the best thresholds calculated on the peak height scale are shown. The accuracy is in all cases higher than $75 \%$. For peak P_72 the sensitivity was $100 \%$, for all other peaks $75 \%$ or higher. The values obtained seem

Table 3 Position of the signals discriminating AATD and COPD without AATD

\begin{tabular}{llccrl}
\hline$\#$ & Area & Norm U & $1 / \mathrm{K}_{0} \mathrm{VS} / \mathrm{cm}^{2}$ & $\mathrm{RT} / \mathrm{s}$ & Nearest analyte \\
\hline 1 & P_72 & 0.169 & 0.627 & 208.1 & unknown \\
2 & P_10 & 0.176 & 0.569 & 6.3 & 1-Butanole \\
3 & P_11 & 0.184 & 0.531 & 6.2 & 2-Butanone \\
4 & P_12 & 0.191 & 0.532 & 8.6 & 2-Propanole \\
5 & P_13 & 0.199 & 0.578 & 8.1 & 2-Hexanone \\
\hline
\end{tabular}


Table 4 Accuracy, sensitivity, specificity, positive and negative predictive values (PPV, NPV) for the peaks found with the lowest rank sum

\begin{tabular}{llllll}
\hline & P_10 & P_11 & P_12 & P_13 & P_72 \\
\hline Best threshold & 0.024 & 0.046 & 0.042 & 0.021 & 0.004 \\
True positive & 13 & 14 & 12 & 13 & 12 \\
False positive & 1 & 2 & 1 & 2 & 0 \\
True negative & 7 & 6 & 7 & 6 & 8 \\
False negative & 4 & 3 & 5 & 4 & 5 \\
Sensitivity (sens) & 0.765 & 0.824 & 0.706 & 0.765 & 0.706 \\
Specificity (spec) & 0.875 & 0.750 & 0.875 & 0.750 & 1.000 \\
NPV & 0.650 & 0.700 & 0.632 & 0.684 & 0.600 \\
PPV & 0.636 & 0.667 & 0.583 & 0.600 & 0.615 \\
a = sens - (1-spec) & 0.640 & 0.574 & 0.581 & 0.515 & 0.706 \\
Accuracy & 0.800 & 0.800 & 0.760 & 0.760 & 0.800 \\
\hline
\end{tabular}

to be promising for a preliminary study with just 25 cases. Generally, the finding needs further confirmation and a higher number of subjects should be included within the study.

\section{Conclusions}

Two different case studies were investigated using $\mathrm{MCC} /$ IMS: before and after AAT substitution and COPD with and without AATD. For the first case, from two patients, 22 different signals were found with rank sum 0.00 , the best value to differentiate. In case two, the 17 samples with AATD and eight with COPD without AATD could be separated by five peaks.

Our preliminary results demonstrate, that distinct patterns of a small number of IMS peaks are found to be useful to separate the classes under investigation. Therefore, MCC/IMS seems to be a promising method for the noninvasive identification as shown before for lung cancer and sarcoidosis patients [19]. But, because of the comparatively low number of subjects included in the preliminary study, a higher number should be investigated. In addition, the relations of the peaks to the analyte need further confirmation, e.g. using parallel measurements using GC/MSD.

Acknowledgements The financial support of the Ministry of Education, Science and Technology (MEST) of the Republic Korea is acknowledged thankfully. Part of the work on this paper has been supported by Deutsche Forschungsgemeinschaft (DFG) within the Collaborative Research Center (Sonderforschungsbereich) SFB 876 "Providing Information by Resource-Constrained Analysis", project TB1 "Resource-Constrained Analysis of Spectrometry Data". In addition, the work was supported partly by the German Federal Ministry of Economics and Technology based on a decision of the German Bundestag within the project KF2368102AKO.

Open Access This article is distributed under the terms of the Creative Commons Attribution Noncommercial License which per- mits any noncommercial use, distribution, and reproduction in any medium, provided the original author(s) and source are credited.

\section{References}

1. Rabe KF et al (2007) Global strategy for the diagnosis, management, and prevention of chronic obstructive pulmonary disease: GOLD executive summary. Am J Respir Crit Care Med 176:532-555

2. Bals R, Koczulla R, Kotke V, Andress J, Blackert K, Vogelmeier C (2007) Identification of individuals with alpha 1-antitrypsin deficiency by a targeted screening program. Respir Med 101:1708-1714

3. Fens N, Zwinderman AH, van der Schee MP, de Nijs SB, Dijkers E, Roldaan AC, Cheung D, Bel EH, Sterk PJ (2009) Exhaled breath profiling enables discrimination of chronic obstructive pulmonary disease and asthma. Am J Respir Crit Care Med 180:1076-1082. doi:10.1164/rccm.200906-0939OC

4. Moser B, Bodrogi F, Eibl G, Lechner M, Rieder J, Lirk P (2005) Mass spectrometric profile of exhaled breath-field study by PTRMS. Respir Physiol Neurobiol 145:295-300. doi:10.1016/j. resp.2004.02.002

5. Thaler ER, Hanson CW (2005) Medical applications of electronic nose technology. Expert Rev Med Devices 2:559-566

6. Wewers MD, Gadek JE (1987) The protease theory of emphysema. Ann Intern Med 107:761-763

7. Bessa V, Darwiche K, Teschler H, Sommerwerck U, Rabis T, Baumbach JI, Freitag L (2011) Detection of volatile organic compounds (VOCs) in exhaled breath of patients with chronic obstructive pulmonary disease (COPD) by ion mobility spectrometry. Int J Ion Mobil Spectrom 14:7-13. doi:10.1007/s12127-011-0060-2

8. Westhoff M, Litterst P, Maddula S, Bödecker B, Rahmann S, Davies AN, Baumbach JI (2010) Differentiation of chronic obstructive pulmonary disease (COPD) including lung cancer from healthy control group by breath analysis using ion mobility spectrometry. Int J Ion Mobil Spectrom 13:131-139

9. Jünger M, Bödeker B, Baumbach JI (2010) Peak assignment in multi-capillary column - ion mobility spectrometry using comparative studies with gas chromatography - mass spectrometry for exhaled breath analysis. Anal Bioanal Chem 396:471-482. doi:10.1007/s00216-009-3168-z

10. Bödecker B, Davies AN, Maddula S, Baumbach JI (2010) Biomarker validation - room air variation during human breath investigations. Int $\mathrm{J}$ Ion Mobil Spectrom 13:177-184. doi:10.1007/s12127-010-0044-7 
11. Westhoff M, Litterst P, Freitag L, Urfer W, Bader S, Baumbach JI (2009) Ion mobility spectrometry for the detection of volatile organic compounds in exhaled breath of patients with lung cancer: results of a pilot study. Thorax 64:744-748. doi:10.1136/ thx.2008.099465

12. Bunkowski A, Boedeker B, Bader S, Westhoff M, Litterst $P$, Baumbach JI (2009) MCC/IMS signals in human breath related to sarcoidosis-results of a feasibility study using an automated peak finding procedure. J Breath Res 3, 046001/046001-046001/ 046010

13. Baumbach JI (2009) Ion, mobility spectrometry coupled with multi-capillary columns for metabolic profiling of human breath. $\mathbf{J}$ Breath Res 3:1-16

14. Ruzsanyi V, Baumbach JI (2005) Analysis of human breath using IMS. Int J Ion Mobil Spectrom 8:5-7

15. Ruzsanyi V, Baumbach JI, Sielemann S, Litterst P, Westhoff M, Freitag L (2005) Detection of human metabolites using multicapillary columns coupled to ion mobility spectrometers. J Chromatogr A 1084:145-151

16. Basanta $M$ et al (2010) Non-invasive metabolomic analysis of breath using differential mobility spectrometry in patients with chronic obstructive pulmonary disease and healthy smokers. Analyst 135:315-320. doi:10.1039/b916 $374 \mathrm{c}$

17. Basanta M, Koimtzis T, Thomas CLP (2006) Sampling and analysis of exhaled breath on human subjects with thermal desorption gas chromatography - differential mobility spectrometry. Int J Ion Mobil Spectrom 9:45-49
18. Gooptu B, Ekeowa UI, Lomas DA (2009) Mechanisms of emphysema in alpha1-antitrypsin deficiency: molecular and cellular insights. Eur Respir J 34(2):475-488

19. Westhoff M, Litterst P, Freitag L, Baumbach JI (2007) Ion mobility spectrometry in the diagnosis of Sarcoidosis: Results of a feasibility study. J Physiol Pharmacol 58:739-751

20. Baumbach JI, Westhoff M (2006) Ion mobility spectrometry to detect lung cancer and airway infections. Spectrosc Eur 18:22-27

21. Baumbach JI (2006) Process, analysis using ion mobility spectrometry. Anal Bioanal Chem 384:1059-1070

22. Bunkowski A, Maddula S, Davies AN, Westhoff M, Litterst P, Bödecker B, Baumbach JI (2010) One-year time series of investigations of analytes within human breath using ion mobility spectrometry. Int J Ion Mobil Spectrom 13:141-148. doi:10.1007/ s12127-010-0052-7

23. Maddula S, Blank L, Schmid A, Baumbach JI (2009) Detection of volatile metabolites of Escherichia coli by multi capillary column coupled ion mobility spectrometry. Anal Bioanal Chem 394:791-800

24. Bödeker B, Baumbach JI (2009) Analytical description of IMSsignals. Int J Ion Mobil Spectrom 12:103-108. doi:10.1007/ s12127-009-0024-y

25. Bödeker B, Vautz W, Baumbach JI (2008) Peak finding and referencing in MCC/IMS - Data. Int J Ion Mobil Spectrom 11:83-88

26. Bödeker B, Vautz W, Baumbach JI (2008) Peak comparison in MCC/IMS - Data - Searching for potential biomarkers in human breath data. Int J Ion Mobil Spectrom 11:89-93

27. Bödeker B, Vautz W, Baumbach JI (2008) Visualisation of MCC/ IMS - Data. Int J Ion Mobil Spectrom 11:77-82 